\title{
Analysis and design consideration of solar steam generation plant using parabolic trough collector
}

\author{
Khaled Bataineh \\ Jordan University of Science and Technology, P.O.Box 3030, Irbid, 22110, Jordan, E-mail: k.bataineh@just.edu.jo \\ cross rof http://dx.doi.org/10.5755/j01.mech.21.5.9834
}

\section{Nomenclature}

$A r$ - aperture area, $\mathrm{m}^{2} ; A$ - thermal heat transfer surface area, $\mathrm{m}^{2} ; C$ - concentration ratio; $c_{p}$ - specific heat, $\mathrm{kJ} / \mathrm{kg} \mathrm{K}$; $D_{o}$ - outer diameter of the receiver, $\mathrm{m} ; q^{\prime \prime}$ - absorbered heat flux, W; $D_{i}$ - inner diameter of the receiver, $\mathrm{m} ; d_{c i}$ - glass cover inner diameter, $\mathrm{m}$; $d_{c o}$ - glass cover outer diameter, $\mathrm{m} ; D_{i}$ - absorber pipe inner diameter, $\mathrm{m} ; F_{R}$ - heat removal factor; $k$-thermal conductivity of the fluid, $\mathrm{W} / \mathrm{mk}$; $h_{\text {latent }}$ - latent heat of evaporation, $\mathrm{W} / \mathrm{kg} ; h$-convection heat transfer coefficient, $\mathrm{W} / \mathrm{m}^{2} \mathrm{k} ; I_{b}$ - direct beam irradiation, W/m ${ }^{2} ; L_{r}$ - receiver tube length, $\mathrm{m} ; L_{h}$ - heat exchanger tube length, m; $N u$ - Nusselt number; $\dot{m}$ - mass flow rate, $\mathrm{kg} / \mathrm{s} ; n$ - day number of the year; $P r$ - Prandtl number; $Q$ - rate of heat transfer, $\mathrm{W} ; r_{b}$ - tilt factor; $R e$ - Reynolds numbers; $T$ - temperature; $V$ - velocity of water in tube in, $\mathrm{m} / \mathrm{s} ; \quad U$ - overall heat transfer coefficient, $\mathrm{W} / \mathrm{m}^{2} \mathrm{~K}$; $U_{l}$ - thermal loss coefficient, $\mathrm{W} / \mathrm{m}^{2} \mathrm{~K} ; W$ - width of aperture, $\mathrm{m}$;

subscripts -

oil - oil; w-water; out - outlet; in - inlet; $a$ - ambient; $c$-cover; amp-average mean temperature; $w$-wind; $f$ - inside receiver tube;

greek letters -

$\theta_{z}$ - zenith angle, ${ }^{\circ} ; \beta$ - surface angle, ${ }^{\circ} ; \gamma$ - intercept factor; $\gamma_{s}$-solar azimuth angle, ${ }^{\circ} ; \delta$-declination angle, ${ }^{\circ}$; $\varepsilon_{p}$ - emissivity of absorber tube surface; $\varepsilon_{c}$ - emissivity of glass cover; $(\tau \alpha)_{b}$ - receiver tube emissivity/absorptivity product; $\phi$ - latitude, ${ }^{\circ} ; \tau$ - reflectivity; $\omega$ - hour angle, ${ }^{\circ}$; $\eta$-efficiency; $\mu$-kinematic viscosity, $\mathrm{m}^{2} / \mathrm{s} ; \Delta T_{l m}-\log$ mean temperature difference in, $\mathrm{K}$.

\section{Introduction}

August Monchot was among the first to generate steam from solar energy to power steam engines between the years 1864 and 1878 [1]. In 1875, Mouchot advanced the design of solar collectors by making them in the form of a truncated cone reflector. John Ericsson constructed in 1880 the first known parabolic trough collector. In 1901, steam generated by heating water inside boiler located at the focal point of collector is used to power a conventional compound engine and centrifugal pump [1]. In 1912 Shuman built $37-45 \mathrm{~kW}$ pumping plant in Egypt where he used long parabolic cylinders to focus sunlight onto a long absorbing tube [1]. Developing parabolic trough regains interest in 1977 due to environmental awareness and technological advancement, and high oil price.

A parabolic trough collector PTC have attracted great attentions and achieved commercial applications, because relatively high collector efficiency is maintained at relatively high temperatures. High temperature steam can be used for thermal power plant where low temperature steam can be used in industrial applications, sterilization, and for powering desalination evaporators. Steam generation via PTC systems is usually obtained by three methods [2]:

1. Pressurized water is heated in the collector and then flashed to steam in a separate vessel using steam-flash concept.

2. Direct steam is generated by allowing water circulation in the receiver.

3. Steam is generated via heat-exchange with heattransfer fluid which is circulated through the collector (Fig. 1).

Each of these systems has its own advantages and disadvantages. Capital costs of direct-steam and flashsteam system is approximately the same [3]. Direct steam generation outperforms flash steam system. In the flash system, higher operating pressure is required to prevent boiling which require a more robust design of collector components, such as receivers and piping. Furthermore, increased operating temperature reduces the thermal efficiency of the solar collector. High pressure is supplied through pump which is required to increase the pressure to prevent boiling. This pumping power is irreversibly dissipated across the flash valve. In direct steam generation, pressure drop is reduced when boiling occur which consequently reduces electrical power consumption. In addition, the latent heat transfer process minimizes the temperature rise across the solar collector which reduced thermal stresses. Recently, once through systems are developed for direct steam generation in which PTC is used inclined at $2-48^{\circ}$ to eliminate instability problems.

To overcome the disadvantages of water systems, a system in which heat-transfer fluid is circulated through collected is used to generate steam via heat exchanger. This method is the predominated method found in steam generation solar systems. The heat transfer fluid should be non-freezing and non-corrosive, system pressures are low and control is straightforward. However, the heat-transfer fluids are usually hard to contain, and most of them are flammable. Heat-transfer fluids are also relatively expensive and present a potential pollution problem which makes them incompatible for food industry applications. Furthermore, water heat transfer characteristics are much better than heat-transfer fluids. They are more viscous at ambient temperatures, are less dense, and have lower specific heats and thermal conductivities than water. These characteristics mean that higher flow rates, higher collector differential temperatures, and greater pumping power are required to obtain the equivalent quantity of energy transport when compared to a system using water. In addition, heat-transfer coefficients are lower, so there is a larg- 
er temperature differential between the receiver tube and the collector fluid. Higher temperatures are also necessary to achieve cost effective heat exchange. These effects result in reduced collector efficiency.

Steam generation from parabolic trough have received significant attention. Thomas [4], Kalogirous et al. [5] and Zarza et al. [6] carried out analyses on the parabolic trough collector systems for steam generation. Their studies showed that the only $48.6 \%$ of the solar radiation energy falling on the collector was used for steam generation, the rest was lost in different forms: (a) collection losses $(41.5 \%)$, (b) thermal losses (6.9\%), and (c) energy losses due to raising the water temperature from environment temperature to $100^{\circ} \mathrm{C}(2.2 \%)$ and for the rig $(0.5 \%)$. Almanza and Lentz [7] built a direct steam generation system by allowing water recirculated in four modules which were connected in series. The first three modules were adapted with copper pipe absorbers covered with black chrome to eliminate the bend due to thermal stress. The measured system efficiency of this system was reached about 30\%. Rovira et al. compared between using Heat Transfer Fluid (HTF) and Direct Steam Generation (DSG). They found that using evaporative DSG configuration is the best choice, since it benefits of both low irreversibility at the heat recovery steam generator and high thermal efficiency in the solar field [8].

The objective of this study is to develop more realistic approach that accurately predicts SSGPs performance. The performance of the system is indicated in terms of amount of steam generated. The amount of steam and its hourly production are important because they influence the cost of system. Mathematical equations are derived based on energy and mass balances for system components. Simulation models are built based on the derived equations. The influence of major parameters on the steam generation is analyzed in detail. Furthermore, this paper presents design optimization so that SSGP can achieve higher reliable continuous steam generation with system components. Finally, this article presents technical design guidelines for SSGPs.

\section{Modelling of solar steam generation}

\subsection{Parabolic trough collector PTC}

The basic element of PTC are (i) the absorber tube located at the focal axis through which the liquid to be heated flows, (ii) the concentric transparent cover, and (iii) the parabolic concentrator. Parabolic trough collectors are used to concentrate the direct solar radiation onto receiver. Among all concentrating technology, the parabolic trough power plants provide over $90 \%$ of the capacity of concentrating solar power plant technology that is in operation or in construction in September 2010. Parabolic through collectors (PTCs) is considered high performance solar collector which can deliver high temperatures up to $400^{\circ} \mathrm{C}$. The absorber is generally a black metal pipe encased in a glass pipe to minimize limit convection heat loss. A selective coating is applied to the metal tube's surface to enhance absorption and reduce emittance. PTCs use one-axis tracking in which the collector tracks the sun in only one direction either from east to west or from north to south. These systems require continuous and accurate adjustment to compensate for the sun's orientation changes.

\subsection{Calculation of solar radiation}

The total incident solar radiation falling on the tube receiver of the parabolic trough has to be determined. The site location, the application season, schedule of operation are the key factors that should be considered when choosing the suitable tracking system. In order to calculate the amount of solar radiation falling into collector surface, several angles are defined:

a) latitude angle $\varphi$ is the angular location north or south of the equator. North of the equator is positive, south is negative, and $-90^{\circ} \leq \phi \leq 90$;

b) declination angle $\delta$ is the angular position of the sun at solar noon on the current day relative to that on the equinox, the declination angle $(\delta)$ is calculated as:

$$
\delta=23.45 \sin \left(360 \frac{284+n}{365}\right)
$$

c) slope $\beta$ is the angle between the collector and the horizontal surface, $0^{\circ} \leq \beta \leq 180^{\circ}$;

d) surface azimuth angle $(\gamma)$ is the deviation of the projection on a horizontal plane of the normal to the surface from the local meridian, with zero being due south, east negative and west positive, $180^{\circ} \leq \gamma \leq 180^{\circ}$;

e) hour angle $\omega$ is the angular displacement of the sun east or west of the local meridian due to rotation of the earth about its axis at $15^{\circ}$ per hour; morning is negative, and afternoon is positive, given as:

$$
\omega=[\text { solartime-12:00]*15 ; }
$$

f) angle of incidence $\theta$ is the angle between the beam radiation on a surface (collector) and the normal to that surface;

g) zenith angle $\theta_{z}$ is the angle between the vertical and the line to the sun. This angle is equal to the angle of incidence for a horizontal surface.

For line focusing collecting systems such as parabolic trough collector, one axis of tracking is needed. For point focusing collecting systems such as solar power tower and dish systems, two axis tracking is needed. In this study, one axis of tracking is used to continuously focus solar radiation into the absorber. Parabolic trough collector tracks solar array in two ways; either (a) about NorthSouth Axis Tracking, or (b) East-West Axis Tracking.

The hourly beam flux incident normally on aperture plane is given by Sukhatme [9] as:

$$
I_{t}=r_{b} I_{b}
$$

where $I_{b}$ is the direct beam irradiation and $r_{b}$ is the tilt factor depends on the incidence angle $(\theta)$. The incidence angle depends on the slope of the collector focal axis about horizontal surface, i.e. the mode of the collector. The tilt factor is given by Sukhatme [9] as:

$$
r_{b}=\frac{\cos \theta}{\cos \theta_{z}} .
$$

The objective of tracking is to minimize the angle of incident $(\theta)$ such that $\cos \theta \approx 1$. In this study, four modes of tracking are investigated. The most widely used 
tracking modes for PTC are:

Mode 1: The focal axis is E-W and horizontal.

In this mode, the collector rotates about horizontal E-W axis and is adjusted once every day. The angle of incident $\theta$ of this mode is given as [9]:

$$
\theta=\cos ^{-1}\left(\sin \delta+\cos ^{2} \delta \cos \omega\right)
$$

Mode 2: The focal axis is E-W and horizontal.

The collector is rotated about a horizontal E-W and adjusted continuously to make minimum angle of incidence all time. The angle of incident $\theta$ for this mode is given as Sukhatme [9]:

$$
\cos \theta=\left(1-\cos ^{2} \delta \sin ^{2} \omega\right)^{1 / 2}
$$

Mode 3: The focal axis N-S and horizontal.

The collector is rotated about a horizontal N-S axis and adjusted continuously to make minimum angle of incidence. For this mode, the angle of incident is given as:

$$
\begin{aligned}
\cos \theta= & (\sin \phi \sin \delta+\cos \phi \cos \delta \cos \omega) \cos \beta+ \\
& +\cos \delta \sin \omega \sin \beta
\end{aligned}
$$

Mode 4: The focal axis is N-S and inclined at a fixed angle equal to the latitude. For this mode, the slope angle $\beta=\phi$ and $\theta=\delta$.

\subsection{Thermal analysis of PTC}

The following assumptions have been made while writing down the energy balance for the PTC:
a. steady-state analysis;
b. radiation flux is uniform along the tube;
c. the temperature drop along the tube and the glass cover are negligible;

d. conventional correlations are used for the convective heat transfer coefficients for oil and air; trough;

e. negligible conduction losses at the ends of each

f. uniform flow;

g. for laminar flow in an annulus, uniform flux was assumed;

h. constant thermal conductance;

i. radiative properties are uniform and independent of direction;

j. the absorptance terms and glass envelope transmittance and emittance are assumed to be independent of temperature.

In order to simplify the mathematics of calculating the thermal losses $Q_{\text {rad }}+Q_{\text {con }}$, it is useful to develop the concept of an overall loss coefficient from the tube absorber to the ambient. To simulate the thermal losses, the thermal network for the tube absorber shown in Fig. 4 is considered.

Implementing the assumptions above with deriving appropriate expressions for the collector efficiency factor $F^{\prime}$, the loss coefficient $U_{l}$, and the collector heat removal factor $F_{R}$, the useful energy $q_{u}$ collected per unit time in a solar collector system can be written as:

$$
q_{u}=F_{R}\left(W-D_{o}\right) L_{r}\left(q^{\prime \prime}-\frac{U_{l}\left(T_{i}-T_{a}\right)}{C}\right)
$$

The heat flux $q$ " absorbed by the receiver is given as [9]:

$$
q^{\prime \prime}=I_{b} r_{b} \rho \gamma(\tau \alpha)_{b}+I_{b} r_{b}(\tau \alpha)_{b}\left(\frac{D_{o}}{W-D_{o}}\right)
$$

where the concentration ratio of the collector $C$ is $\frac{W-d_{c o}}{\pi D_{o}}, F_{R}$ is the heat removal factor given as:

$$
\begin{aligned}
& F_{R}=\frac{\dot{\mathrm{m}} C_{p}}{A_{r} U_{L}}\left[1-\operatorname{EXP}\left(\frac{-A r U_{L} F^{\prime}}{m c_{p, o i l}}\right)\right] ; \\
& F^{\prime}=\frac{1}{U_{L}\left[\frac{1}{U_{L}}+\frac{D_{o}}{D_{i} h_{f}}\right]} .
\end{aligned}
$$

The heat transfer coefficient $h_{f}$ is given as:

$$
h_{f}=N u \frac{k}{D_{i}} .
$$

For laminar flow, the Nusselt number is $N u=3.66$, while for turbulent flow, the Nusselt number can be calculated by the Dittus - Boelter equation as:

$$
N u=0.023 \operatorname{Re}^{0.8} \operatorname{Pr}^{0.4}
$$

where Reynolds number $\operatorname{Re}$ is $\operatorname{Re}=\frac{V D_{i}}{v}$, and fluid velocity is $V=\frac{4 m}{\pi D_{i}^{2} \rho}$, Prandtl number $\operatorname{Pr}$ is $\frac{c_{p} v \rho}{k}$, the heat flux $q^{\prime \prime}$ absorbed by the receiver is given as [9]:

$$
q^{\prime \prime}=I_{b} r_{b} \rho \gamma(\tau \alpha)_{b}+I_{b} r_{b}(\tau \alpha)_{b}\left(\frac{D_{o}}{W-D_{o}}\right) .
$$

The heat loss is given as [9]:

$$
q_{\text {loss }}=W L_{r} q^{\prime \prime}-q_{u}
$$

The thermal loss coefficient $\left(U_{l}\right)$ can be obtained by using the electric circuit analogy (heat balance):

$$
U_{l}=\frac{q_{\text {loss }}}{\pi L_{r} d_{o}\left(T_{o}-T_{a}\right)} .
$$

The thermal loss coefficient $\left(U_{l}\right)$ can be calculated by iterative solution or by using semi empirical formula to eliminate the need of iterative calculation. In this study, we utilized the empirical equation developed by Mullick and Nanda [10] which is based on calculation for a large number of cases covering a bored range of condition encountered with cylindrical parabolic trough. 


$$
\begin{aligned}
& \frac{1}{U_{l}}=\frac{1}{C_{3}\left(T_{p m}-T_{c}\right)^{0.25}+\left[\frac{\sigma\left(T_{p m}^{2}+T_{c}\right)\left(T_{p m}+T_{c}\right)}{\left.\left\{\frac{1}{\varepsilon_{p}}+\frac{D_{o}}{d_{c i}}\left(\frac{1}{\varepsilon_{C}}-1\right)\right\}\right]}\right.}+ \\
& +\left(\frac{D_{o}}{d_{c o}}\right)\left(\frac{1}{h_{w}+\sigma \varepsilon_{c}\left(T_{c}^{2}+T_{a}^{2}\left(T_{c}+T_{a}\right)\right)}\right) .
\end{aligned}
$$

The constant $C_{3}$ has been obtained from the correlation of Raithby and Hollands [11] and is given by the expression:

$$
C_{3}=\frac{17.74}{\left(T_{p m}+T_{c}\right)^{0.4} D_{o}\left(D_{o}^{-.75}+d_{c i}^{-0.75}\right)} .
$$

The cover temperature $T_{c}$ is given by:

$$
\begin{aligned}
\left(\frac{T_{c}-T_{a m p}}{T_{p m}-T_{a m p}}\right)= & 0.163\left(\frac{D_{o}}{d_{c o}}\right)^{0.4} h_{w}^{-0.67} \times \\
& \times\left[2-3 \varepsilon_{p}+\frac{\left(1+3 \varepsilon_{p}\right) T_{p m}}{100}\right] .
\end{aligned}
$$

For the range $513 \mathrm{~K}<T_{p m}<623 \mathrm{~K}$. The outlet temperature of oil from the absorber of collector is given as:

$$
T_{o}=\frac{q_{u}}{\dot{m} c_{p}}+T_{o, i n}
$$

\subsection{Steam generation with PTCs}

The schematic diagram of solar steam generator shown in Fig. 1 is basically composed of three elements: the solar system, the steam generator, and the industrial process.

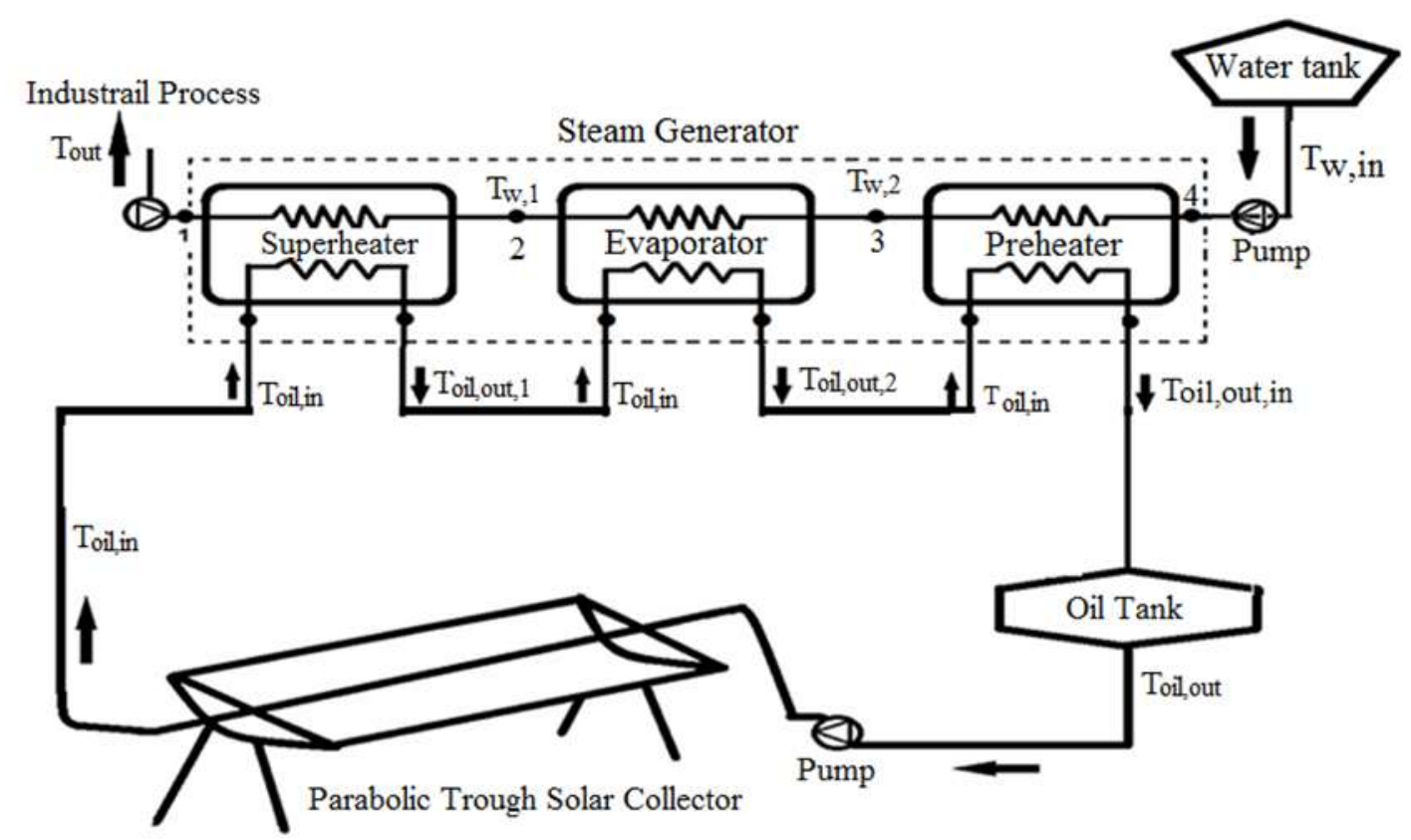

Fig. 1 Schematic diagram for solar steam generation via heat exchanger (Nodal analysis of temperature)
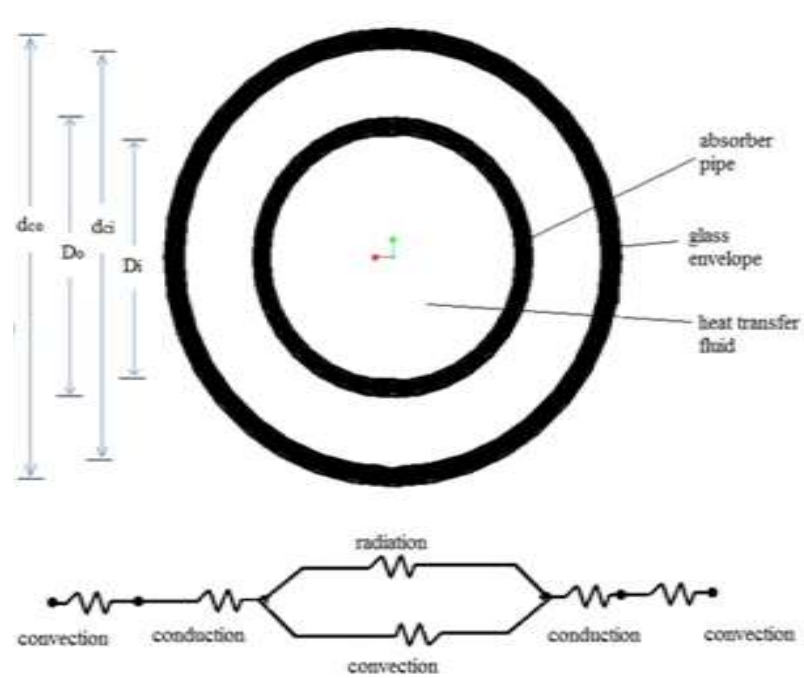

Fig. 2 Heat transfer through absorber
The solar system is composed of a parabolic trough solar collector with HTF circulating inside the absorber tube located at it focal line. An oil-water heat exchanger unit is used to generate the superheated steam. The steam generator consists of three stages:

- preheater: where water is preheated to a temperature close to evaporation;

- evaporator: where the preheated water is evaporated and converted into saturated steam;

- super heater: the saturated steam produced in the evaporator is heated to the required temperature.

\subsection{The heat exchanger design equation}

Fig. 3 illustrates the heat transport processes in the heat exchange system. In Fig. 3, process 1-2, process 2-3 and process 3-4 are overheating process, evaporating process and, and preheating process respectively. The 
thermal energy absorbed by the water in these three processes are given as [13]:

- $\quad$ For preheater (process 1-2)

The rate of heat transfer between the two fluids in the heat exchanger (I):

$$
\begin{aligned}
& Q_{1 \rightarrow 2}=\dot{m}_{w} c_{p, w}\left(T_{w, 2}-T_{w i n}\right) ; \\
& Q_{1 \rightarrow 2}=\dot{m}_{1, \text { oil }} c_{p, \text { oil }}\left(T_{\text {oil }, \text { in }}-T_{\text {oil }, \text { out }, 3}\right) ; \\
& Q_{1 \rightarrow 2}=U A \Delta T_{l m, 1 \rightarrow 2} ;
\end{aligned}
$$

$$
\begin{aligned}
& \Delta T_{l m, 1 \rightarrow 2}=\frac{\left(T_{\text {oil ,in }}-T_{w, \text { in }}\right)-\left(T_{\text {oil }, \text { out }, 3}-T_{w, \text { out }}\right)}{\ln \left(\left(T_{\text {oll }, \text { in }}-T_{w, \text { in }}\right) /\left(T_{\text {oil }, \text { out }, 3}-T_{w, \text { out }}\right)\right)} ; \\
& A=n \pi D L_{h} .
\end{aligned}
$$

All variables are known expect $\left(T_{w, 1}, T_{\text {oil,out }, 1}\right.$, $Q_{1 \rightarrow 2}$ ). Stocker [13] provided equation for the unknown variable as:

$$
T_{w, 1}=\frac{\left[\left(\left(e^{D_{1}}-1\right) T_{o i l, \text { in }}\right)+\left(\left(e^{D_{1}}\left(\frac{\dot{m}_{w, \text { in }} c_{p, w, i n}}{\dot{m}_{1, \text { oil }} c_{p, \text { oil in }}}+1\right) T_{w, \text { in }}\right)\right)\right]}{\left(\frac{\dot{m}_{w, \text { in }} c_{p, w, i n}}{\dot{m}_{1, \text { oil }} c_{p, \text { oil in }}}\right) e^{D_{1}}},
$$

where $\quad D_{1}=U A\left(\frac{1}{c_{p, w, i n} \dot{m}_{w}}-\frac{1}{c_{p, \text { oil in }} \dot{m}_{1, \text { oil }}}\right), \quad$ and $Q_{1 \rightarrow 2}=\dot{m}_{w} c_{p, w}\left(T_{w 1}-T_{w, i n}\right)$, hence:

$$
T_{\text {oil }, \text { out }, 3}=T_{\text {oil }, \text { out }, 2}-\frac{Q_{1 \rightarrow 2}}{\dot{m}_{1, \text { oil }} c_{p, o i l, \text { in }}} .
$$

- $\quad$ For evaporator (process 2-3)

The rate of heat transfer between the two fluids in the heat exchanger (II) is given by [18] as:

$$
\begin{aligned}
& Q_{2 \rightarrow 3}=\dot{m}_{2, \text { oil }} c_{p, \text { oil }, \text { in }}\left(T_{\text {oil }, \text { out }, 1}-T_{\text {oil }, \text { out }, 2}\right) ; \\
& Q_{2 \rightarrow 3}=\dot{m}_{w} h_{\text {latent }} ; \\
& Q_{2 \rightarrow 3}=U A \Delta T_{l m, 2 \rightarrow 3},
\end{aligned}
$$

where, $\Delta T_{l m}$ is the log mean temperature difference is given as:

$$
\Delta T_{l m, 2 \rightarrow 3}=\frac{\left(T_{o i l, \text { in }}-T_{w, 1}\right)-\left(T_{o i l, o u t, 2}-T_{w, 2}\right)}{\ln \left(\left(T_{o i l, \text { in }}-T_{w, 1}\right) /\left(T_{\text {oil }, \text { out }, 2}-T_{w, 2}\right)\right)},
$$

but $T_{w, 2}=T_{w, 1}$

$$
\Delta T_{l m, 2 \rightarrow 3}=\frac{T_{o i l, \text { in }}-T_{\text {oil }, \text { out }, 2}}{\ln \left(\left(T_{\text {oil }, \text { in }}-T_{w, 2}\right) /\left(T_{\text {oil }, \text { out }, 2}-T_{w, 2}\right)\right)},
$$

where, the subscripts are according to Fig. 1.Stocker [17] presented direct equation for calculating the unknown variables as:

$$
\begin{aligned}
& T_{\text {oil }, \text { out }, 2}=T_{w, 1}+\left(T_{o i l, o u t, 1}-T_{w, 1}\right) \times e^{D_{2}} ; \\
& D_{2}=\frac{U A}{c_{p, o i l, \text { in }} \dot{m}_{2, \text { oil }}} ; \\
& Q_{2 \rightarrow 3}=\dot{m}_{2, \text { oil }} c_{p, \text { oil , in }}\left(T_{\text {oil }, \text { in }}-T_{o i l, o u t, 2}\right) ; \\
& h_{\text {latent }}=\frac{Q_{2 \rightarrow 3}}{\dot{m}_{w}} .
\end{aligned}
$$

- $\quad$ For super heater (process 3-4)

The rate of heat transfer between the two fluids in the heat exchanger III is given by [16] as:

$$
\begin{aligned}
& Q_{3 \rightarrow 4}=\dot{m}_{\text {steam }} c_{p, \text { steam }}\left(T_{\text {out }}-T_{w 2}\right) ; \\
& Q_{3 \rightarrow 4}=\dot{m}_{3, \text { oil }} c_{p, \text { oil }}\left(T_{\text {oil }, \text { in }}-T_{\text {oil }, \text { out }, 3}\right) ; \\
& Q_{3 \rightarrow 4}=U A \Delta T_{l m, 3 \rightarrow 4} ; \\
& \Delta T_{l m, 3 \rightarrow 4}=\frac{\left(T_{\text {oil }, \text { out }, 3}-T_{\text {out }}\right)-\left(T_{\text {oil }, \text { in }}-T_{w, 2}\right)}{\ln \left(\left(T_{\text {oil }, \text { out }, 3}-T_{\text {out }}\right) /\left(T_{\text {oil }, \text { in }}-T_{w, 2}\right)\right)},
\end{aligned}
$$

but the specific heat for steam $c_{p \text {,steam }}$ is function with temperature are given by [17] as:

$$
\begin{aligned}
c_{p, \text { steam }, 1}= & 4.214-2.286 \times 10^{-3} T_{w, 2}+4.991 \times 10^{-5} T_{w, 2}^{2}- \\
& -4.519 \times 10^{-7} T_{w, 2}^{3}+1.857 \times 10^{-9} T_{w, 2}^{4} .
\end{aligned}
$$

[13] as:

$$
T_{\text {out }}=\frac{\left[\left(\left(e^{D_{3}}-1\right) T_{\text {oil }, \text { out }, 2}\right)+\left(\left(e^{D 3}\left(\frac{\dot{m}_{w} c_{p, w, i n}}{\dot{m}_{\text {oil }} c_{p, \text { oil in }}}+1\right) T_{w, 1}\right)\right)\right]}{\left(\frac{\dot{m}_{w, \text { in }} c_{p, w, \text { in }}}{\dot{m}_{3, \text { oil }} c_{p, \text { oil in }}}\right) e^{D_{3}}},
$$


where

$$
\begin{aligned}
& D_{3}=U A\left(\frac{1}{c_{p, w . i n} \dot{m}_{w}}-\frac{1}{c_{p . \text { oil.in }} \dot{m}_{\text {oil }}}\right) ; \\
& Q_{3 \rightarrow 4}=\dot{m}_{w} c_{p, w}\left(T_{w, 2}-T_{w, 1}\right) ; \\
& T_{\text {oil }, \text { out }, 3}=T_{\text {oil }, \text { out }, 2}-\frac{Q_{3 \rightarrow 4}}{\dot{m}_{3, \text { oil }} c_{p, \text { oil }, \text { in }}}
\end{aligned}
$$

\subsection{Steam generation plant parameters}

A. Site: the steam generation is assumed to be located in Irbid, Jordan (on $35.7^{\circ}$ longitudes and $32.5^{\circ}$ latitude).

B. PTC: the collector optical data are listed in Table 1. The base material chosen is $321 \mathrm{H}$ stainless steel due to its strength and its ability to resist bending due to thermal stresses.
C. The thermal oil: The thermal oil used is THERMINOL66 which is high performance stable synthetic heat transfer fluid offering extended life. This oil can operate at temperatures up to $390^{\circ} \mathrm{C}$. The physical properties depend on the temperature and given as [13]:

$$
\begin{aligned}
& c_{p}=0.003313 T+8.970785 \times 10^{-7} T^{2}+1.496005 ; \\
& k=-0.000033 T-0.00000015 T^{2}+0.118294
\end{aligned}
$$

The kinematic viscosity $\mu(\mathrm{m} / \mathrm{s})$ is:

$$
\mu=10^{-6} e^{\left(\frac{586.375}{T+62.5}-2.2809\right)},
$$

where the temperature $T$ is measured in $\left({ }^{\circ} \mathrm{C}\right)$.

D. Heat exchanger: a shell-and-tube exchanger with one shell and one tube pass is used. Table 2 lists the standard dimension of the heat exchanger chosen.

Table 1

Geometrical and optical parameters for the parabolic trough collector

\begin{tabular}{|c|c|c|c|c|c|c|c|c|c|c|c|}
\hline$F, \mathrm{~m}$ & $\varnothing,{ }^{\circ}$ & $W, \mathrm{~m}$ & $A_{a p}, \mathrm{~m}^{2}$ & $L_{r}, \mathrm{~m}$ & $C$ & $D_{r, \text { int }}, \mathrm{m}$ & $D_{r, \text { ext }}, \mathrm{m}$ & $D_{c o}, \mathrm{~m}$ & $\rho$ & $\varepsilon_{r}$ & $K_{r}, \mathrm{~W} / \mathrm{m} .{ }^{\circ} \mathrm{C}$ \\
\hline 0.25 & 90 & 1.9 & 1.9 & 18 & 10.3 & 0.066 & 0.07 & 0.09 & 0.85 & 0.9 & 54 \\
\hline
\end{tabular}

Table 2

Geometrical and thermal parameters for the heat exchanger (one shell, one pass)

\begin{tabular}{|c|c|c|c|cc|}
\hline Shell diameter, $\mathrm{m}$ & Tube length $L_{h}, \mathrm{~m}$ & No. of tubes & $\begin{array}{c}\text { Tube diameter, } \\
\mathrm{m}\end{array}$ & \multicolumn{2}{|c|}{$\begin{array}{c}U, \mathrm{~m}^{2} . \mathrm{k} \\
\text { Superheated, Evaporation, preheating }\end{array}$} \\
\hline 0.2032 & 1.5 & 50 & 0.015875 & 150 & 450 \\
\hline
\end{tabular}

\section{Results and discussion}

A parametric study is performed to evaluate the performance of SSGP. Simulation models are built based on mass and energy balances applied to every component of the system. The model simulates the hourly thermal behavior of all system components.

The beam solar radiation on a horizontal surface for the Irbid (latitude $=32.2^{\prime} \mathrm{N}$ and Longitude $35 \mathrm{~W}$ ) for the year of 2014 is used in this study. Result of solar radiation measurement is shown in Fig. 4. Four modes of tracking are investigated to order to determine the best orientation for maximum solar radiation. Fig. 5 presents the monthly average daily beam solar radiation available at the collector. It can be seen in Fig. 5 that Mode 4 has the highest annual solar radiation. Furthermore, if the application is mostly needed during summer period, Mode 3 provides the highest solar energy. If the application is designed to run during winter time, mode 1 will be the best option since it does not required complex tracking. All following are made according to Mode 3.

The amount of steam generation is the most important quantity. The hourly production of steam should be predicted. The desired steam temperature is set equal to $130^{\circ} \mathrm{C}$. Fig. 6 shows the annual hourly steam production. The HTF mass flow rate is set equal to $0.04 \mathrm{~kg} / \mathrm{s}$ during summer period while it is set equals to $0.02 \mathrm{~kg} / \mathrm{s}$ for winter time. The simulations results show that during summer the solar steam plant is able to generate over $2400 \mathrm{~kg}$ of steam daily. Furthermore, Modes 3 tracking allow almost uniform steam production. The lowest steam production is during January with daily average around $994 \mathrm{~kg}$. Furthermore, it can be seen in Fig. 6, b, that the average day long production exceeds 8 hours during summer period with average rate of production exceeds $250 \mathrm{Kg} / \mathrm{hr}$. As for the winter period, the operational hours of the solar steam generation plant is less than 8 hours per day. The steam production during winter varies significantly. This may be explained due to existence of clouds during winter period. In order to have uniform steam generation rate, the plant should be equipped with thermal storage tank and variable speed pump controlling the mass flow rate of HTF in order to maintain specified temperature inside the thermal storage tank. An auxiliary boiler should be incorporated to supply heat when solar radiation levels are too low.

The effect of mass flow rate of HTF on steam production is investigated. Decreasing mass flow of the oil circulating inside the absorber tubes allows the oil to reach higher temperature values. The maximum temperature of the oil is set equals to $400^{\circ} \mathrm{C}$. Higher temperature values of the oil leads to high thermal losses. On the other hand, reducing the mass flow rate decreases the energy carried by the oil which is required to generate steam. This opposite effect requires simulation to accurately determine the effect of mass flow rate of HTF. 


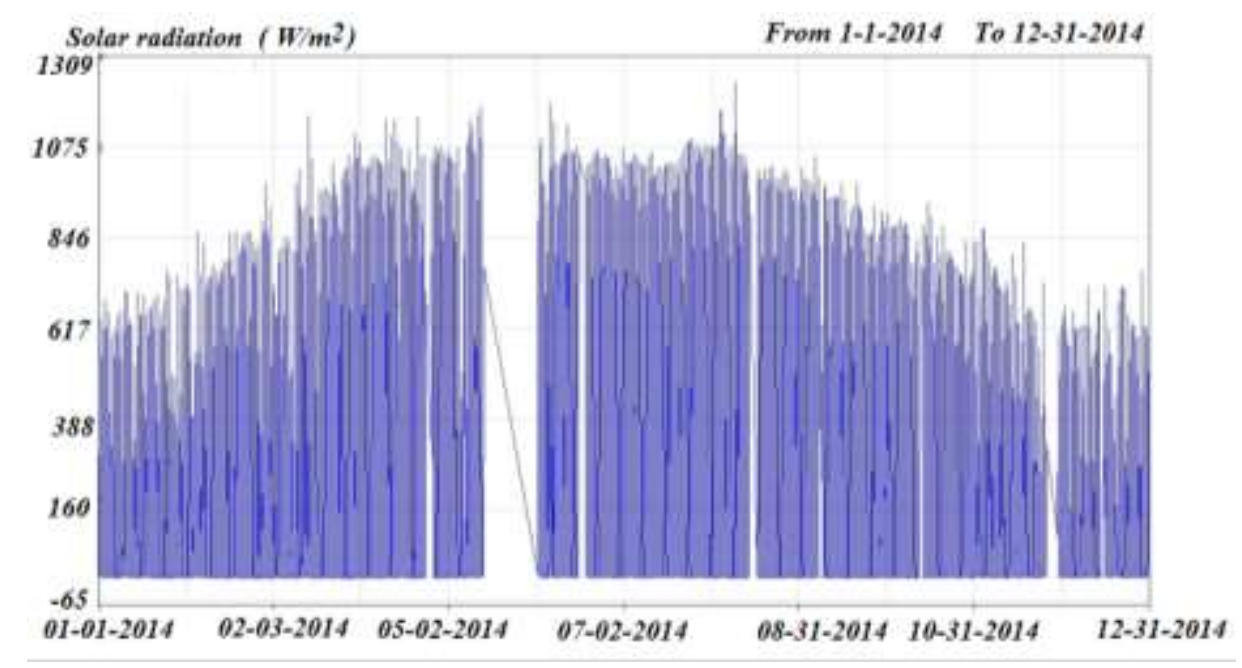

Fig. 4 Solar intensity in Irbid for 2014

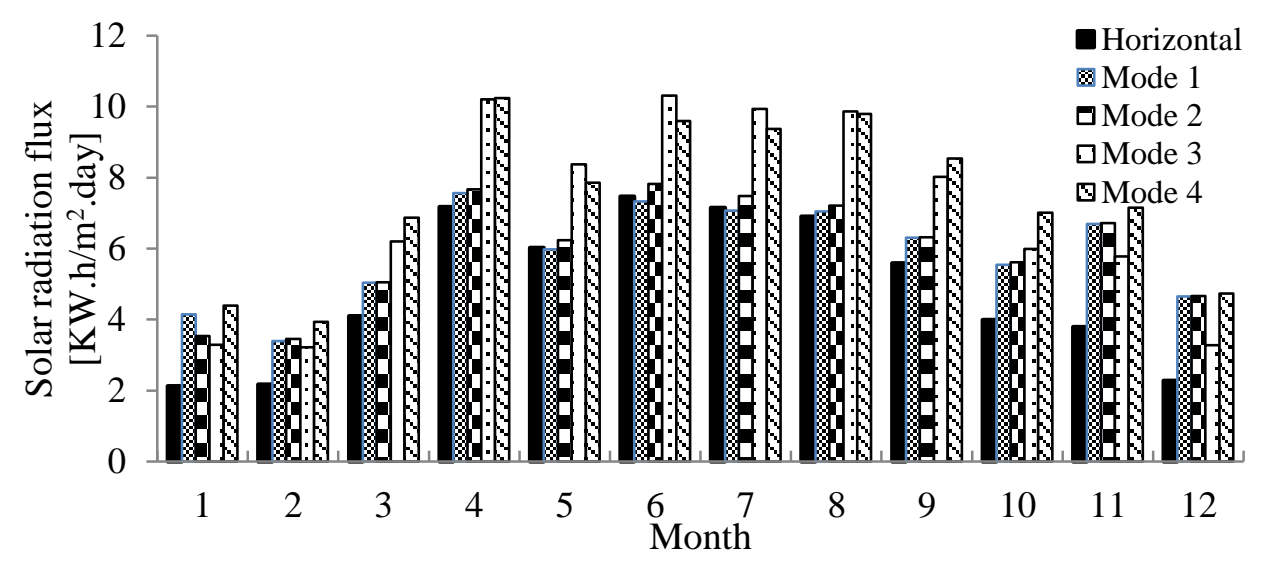

Fig. 5 Monthly average daily solar radiation for the modes studied

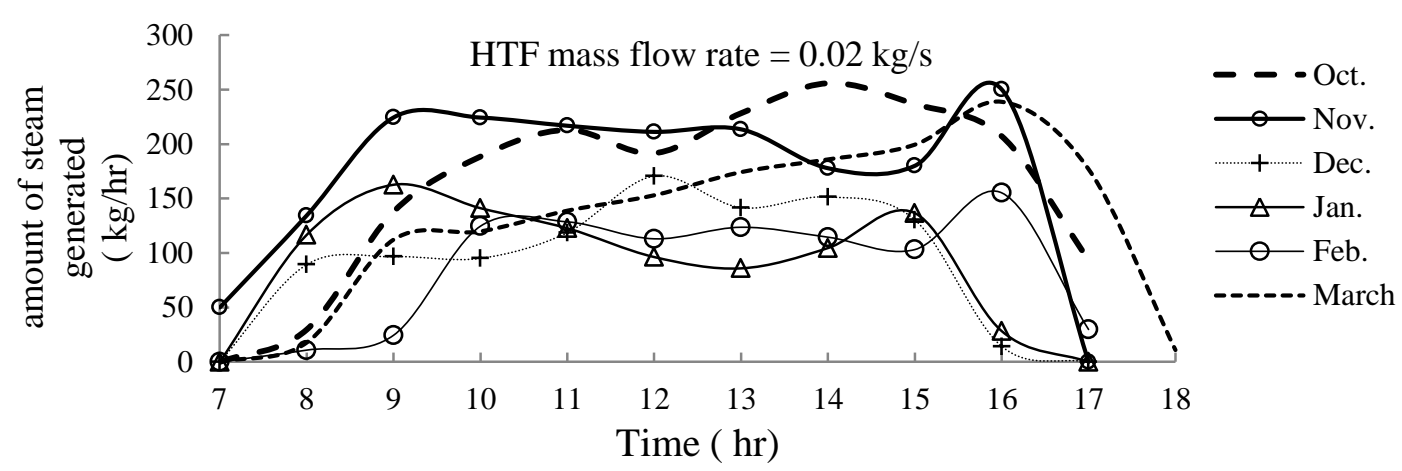

a

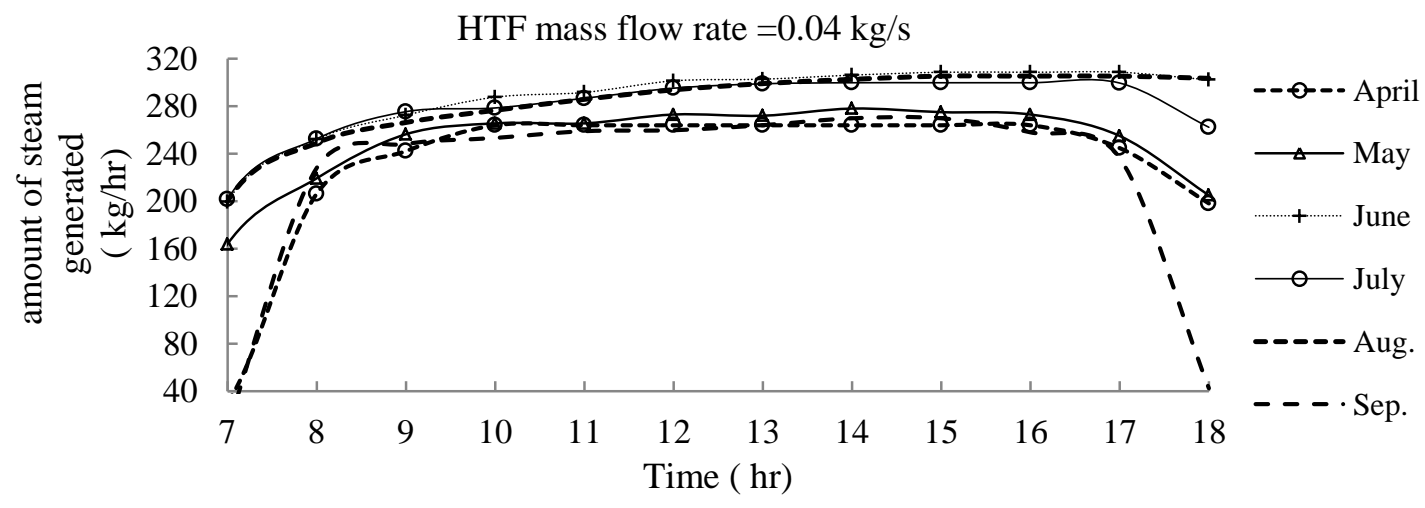

Fig. 6 Annual hourly steam generation (steam at temperature $130^{\circ} \mathrm{C}$ ): a) during winter; b) summer 


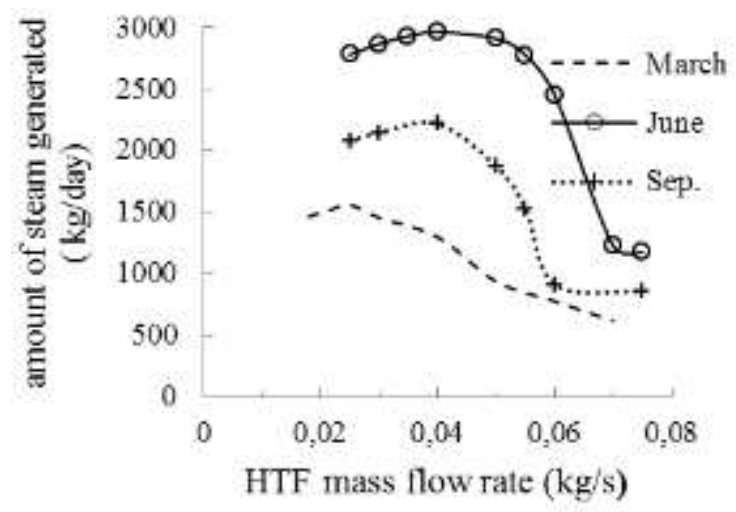

Fig. 7 Daily stream generation as a function of oil mass flow rate

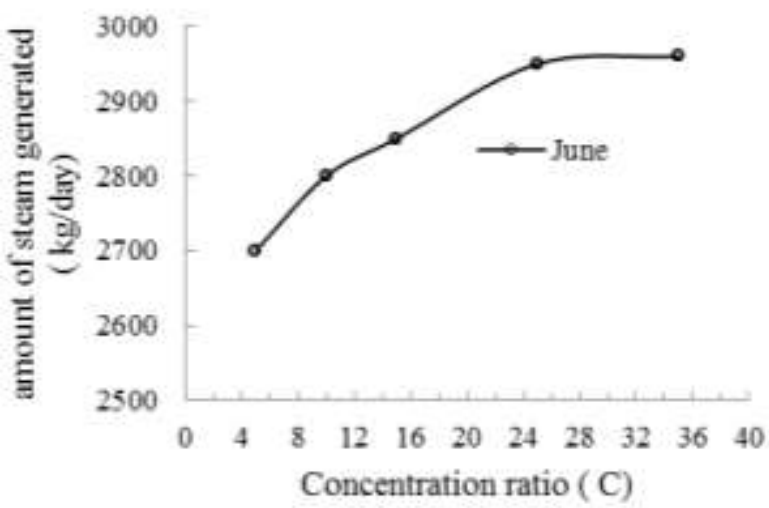

Fig. 8 Effect of concentration ratio on amount of steam generation

Fig. 7 shows the amount of steam generation as a function of mass flow rate of the oil. The simulation results show that there is optimal mass flow rate for each month. For example, the optimal HTF mass flow rate for March is $0.022 \mathrm{~kg} / \mathrm{s}$. For this mass flow rate, the plant is able to generate over $1500 \mathrm{~kg}$ of steam.

Finally, simulations are conducted to study the effect of concentration ratio on the amount of steam generation. Increasing the concentration ratio has two opposite effect on the performance of the steam generation plant. Higher values of $C$ corresponding to smaller area which reduces the heat loss. At the same time, higher values of $C$ allow the HTF temperature reaches higher values which leads to increases heat losses. It is worth mentioning here that the cost of PTC is proportional to the concentration ratio. Fig. 8 shows that the amount of steam generation is directly proportional the concentration ratio. Furthermore, it can be seen in Fig. 8 that the amount of steam generation starts to level off at high values of $C$. This can be explained by referring to Eqs. (8)-(9). The first term on the right hand side in Eq. (9) represents the incident beam radiation absorbed in the absorber tube after reflection, and the second term represents the absorbed incident beam radiation which falls directly on the absorber tube. The second term is small in comparison with the first, but cannot be ignored when the concentration ratio is small. The third term represents in Eq. (8) represents the loss by convection and radiation. The heat loss coefficient $U_{l}$ increases with increasing the fluid temperature circulating inside the receiver tube. The last term in Eq. (8) shows that the heat loss increase with increasing $U_{l}$ and decreases with increasing $C$. Simu- lations results indicates that the net effect of increasing $C$ has significant positive effect up to certain values. After that, the effect becomes insignificant.

\section{Conclusions}

This paper presents a transient thermal model for a solar steam generation system via parabolic trough collector. The influences of several designing and operating parameters on the performance of the collector field as well as the whole system are examined. It was found that sun tracking modes, mass flow rate of HTF, and collector concentration ratio plays important roles in determining the amount of the steam generation. It is found that higher the concentration ratio leads to higher amount of steam generated. Furthermore, simulations results showed there is an optimal mass flow rate for HTF. Finally, PTC of collector area of $38 \mathrm{~m}^{2}$ is able to produce between 950 and $3000 \mathrm{~kg}$ /day of steam at temperature $130^{\circ} \mathrm{C}$.

\section{References}

1. Meinel, A.B.; Meinel, M.P. 1976. Applied Solar Energy: An Introduction. Reading, MA: Addison-Wesley, $651 \mathrm{p}$.

2. Kalogirou, S.; Lloyd, S.; Ward, J. 1997. Modelling optimization and performance evaluation of a parabolic trough collector steam generation system, Solar Energy 60(1): 49-59. http://dx.doi.org/10.1016/S0038-092X(96)00131-4.

3. Hurtado, P.; Kast, M. 1984. Experimental study of direct in-situ generation of steam in a line focus solar collector, SERI.

4. Thomas, A. 1996. Solar steam generating systems using parabolic trough concentrators, Energy Convers Manage, 37(2): 215-245. http://dx.doi.org/10.1016/0196-8904(95)00162-7.

Kalogirou, S; Lloyd, S; Ward, J. 1997. Modelling, optimisation and performance evaluation of a parabolic trough solar collector steam generation system, Solar Energy 60(1): 49-59. http://dx.doi.org/10.1016/S0038-092X(96)00131-4.

5. Zarza, E.; Valenzuela, L.; Leo'n J.; Hennecke, K.; Eck, M.; Weyers, H. 2004. Direct steam generation in parabolic troughs: final results and conclusions of the DISS project, Energy 29(5-6): 635-644. http://dx.doi.org/10.1016/S0360-5442(03)00172-5.

6. Almanza, R.; Lentz, A. 1998. Electricity production at low powers by direct steam generation with parabolic troughs, Solar Energy 64(1-3): 115-120. http://dx.doi.org/10.1016/S0038-092X(98)00046-2.

7. Rovira, A.; Montes, M.J., Varela, F.; Gil, M. 2013. Comparison of heat transfer fluid and direct steam generation technologies for integrated solar combined cycles, Applied Thermal Engineering 52(2): 264-274. http://dx.doi.org/10.1016/j.applthermaleng.2012.12.008

8. Nayak, J.K.; Sukhatme, S.P. 2008. Solar Energy: Principles of Thermal Collection and Storage, Third edition, McGraw-Hill, 2008. 460 p.

9. Mullick, S.C.; Nanda, S.K. 1989. An improved technique for computing heat loss factor of a tubular absorber, Solar Energy 42(1): 1-7.

http://dx.doi.org/10.1016/0038-092X(89)90124-2. 
10. Raithby, G.D.; Hollands, K.G.T. 1975. General method of obtaining approximate solutions to laminar and turbulent free convection problems, Irvine, T.F., and Hartnett, J.P., Eds., Advances in Heat Transfer 11: 265-315, Academic Press, New York, NY.

11. Incropera, F.P.; Dewitt, D.P.; Bergman, T.L.; Lavine, A.S. 2007. Fundamentals of Heat and Mass Transfer, 6ed Edition, John Wiley and Sons, New York.

12.Stoecker, W.F. 1989. Design of Thermal Systems, 3rd Edition, McGraw-Hill, Inc., 528 p.

\section{Khaled Bataineh}

\section{ANALYSIS AND DESIGN CONSIDERATION OF SOLAR STEAM GENERATION PLANT USING PARABOLIC TROUGH COLLECTOR}

S u m m a r y

This paper investigates the annual performance of solar steam generation plant SSGP using parabolic trough collectors via heat exchanger. A transient thermal model for the system is developed. Dynamic simulation of the SSGP is carried out under different operating and geometrical conditions to investigate the plant performance. Several tracking modes are proposed and the optimal configuration for the considered site is determined. The effects of several key parameters, including the flow rate of thermal oil in the absorber tube, concentreation ratio, on the performance of the SSGP based on the meteorological data of Irbid city were examined. Designing optimization of SSGP is carried out. The study shows that using PTC with area of $38 \mathrm{~m}^{2}$ can generate over $950 \mathrm{~kg}$ of steam above $130^{\circ} \mathrm{C}$ in winter time and over $3000 \mathrm{~kg}$ during summer time. Finally, it was found that using PTC for steam generation is reliable system for industrial application operated during daytime.

Keywords: Solar steam generation, parabolic trough collector, thermal losses, performance, heat exchanger.

Received February 11, 2015 Accepted April 21, 2015 